\title{
Study on the Construction of Economics and Management Labs in Universities of Northern Shaanxi from the Perspective of Training of Application-oriented Talent
}

\author{
Jiang Liu" a ${ }^{1,}$, Hui Ma ${ }^{1, b}$ and Guotao Zhang ${ }^{1, c}$ \\ ${ }^{1}$ School of Management, Yulin University, China, 719000 \\ a52186531@qq.com, ${ }^{\mathrm{b}}$ 57696900@qq.com, ${ }^{\mathrm{c}}$ 153031844@qq.com
}

\begin{abstract}
Keywords: Training of application-oriented talent; Northern Shaanxi; Construction; Laboratory of economics and management
\end{abstract}

\begin{abstract}
From the perspective of training of application-oriented talent, based on the analysis of the status of the economics and management laboratory of Yulin college and the beneficial experience of the advancement of such laboratories in the related universities, the paper puts forward concrete suggestions and measures for the transformation and development, which will be analyzed from four aspects: infrastructure construction of laboratory, optimizing of teaching staff, improving of laboratory organization and management, building of the teaching system. Through the experimental teaching practice training, students can gradually master the professional practical skills in finance and accounting, which will provide guarantees for students to benefit from the theoretical knowledge into application ability.
\end{abstract}

\section{Introduction}

With the economic development into the new normal, talent supply and demand relations profound changes in the face of profound economic restructuring, industrial upgrading to speed up the pace of the community on the economic management talent and application of professional competence are put forward new requirements. As an important base of teaching and scientific research in colleges and universities, the construction and management level of the laboratory is not only an important manifestation of the level of teaching and scientific research in colleges and universities, but also an important task facing the transformation and development of talent training mode in colleges and universities in the new period. Therefore, the design of high-quality experimental management model, the construction of high-quality economic management laboratory, has become an important basis for cultivating talents of economics and management.

\section{The Current Situation of Construction of Laboratories in Yulin College}

Management Department in Yulin College of has Accounting, Financial management, Marketing, Tourism management, four undergraduate majors so far. To 2015, management department has completed the business management and tourism management two departments, which are the experimental center, respectively, under the three experimental sub-rooms. Throughout the past five years, the construction of laboratories and management status, the main problems are as follows.

The Bondage of Concept, Lack of Investment. The laboratory is an important base for cultivating high-level talents, and it also plays an important role in teaching. Yet, compared with science and engineering laboratories, the development of economics and management laboratories is late, and a great number of universities are more willing to put the funds into science and engineering laboratories which are in high economic efficiency. In addition, for the management of professional terms, from the objective conditions to the subjective reasons, the prevalence of heavy knowledge transfer, light capacity training, heavy theoretical teaching, light experimental teaching errors, ignoring the students' initiative and creativity, laboratory construction And experimental teaching is in a neglected position and a serious backward state. Because of these misunderstandings, the construction of specialized laboratories lags behind the long-term needs of personnel training, and graduates who go to work are of poor adaptability as well as long adaptation. 
It is difficult for them to meet the needs of the work, and it is difficult to quickly come into the working state.

A Lack of experimental Teachers Lead to Difficulties in Coaching Students well. At present, compared with science and engineering, economy and management specialty is later to set up experimental courses; What is more, management disciplines generally do not attach importance to experimental teaching for a long time. They just deem it as subordinate. Many highly educated teachers therefore are reluctant to engage in high-quality experimental teaching. In addition, the economy and management specialty laboratory courses are comprehensive and cross-disciplinary, teachers who only know two or three professional courses are difficult to solve the multidisciplinary, cross-experiment problems raised by students. Therefore, in the experimental teaching, teachers need to have a solid theoretical knowledge and to understand a certain social practice. They should not only know the subject knowledge but also the understanding of other related disciplines. Experimental faculties lack of full-time teachers and double-certificated teachers.

The experiment's Content and Links Need to Reform and Innovate. The experimental teaching of economy and management specialty is basically an adjunct to the theory teaching. The content of the experiment is usually confined to the curriculum. Sometimes the knowledge points are single and not systematic. It is in fact the verification of the theoretical knowledge. Experimental method is the students follow the instructions specified in the experimental instructions to complete the experiment. During the entire experimental process, students are passive. Even some of the so-called "comprehensive, experimental design" is only the teachers reset the data, and the students follow the steps to do it again. Students are clear about the experimental process and results before the experiment, no new ideas at all. So the students are not interested in experimental content and methods. Obviously, this experimental teaching is difficult to train students' practical and comprehensive quality, and it runs the opposite direction with our training application-oriented talents.

Management Methods and mechanism is backward, Lack of open and shared Resources. In laboratory construction, efficient laboratory management and operation mechanism is a necessary condition for the smooth development of experimental teaching in colleges and universities. Because of the experimental management model of science and engineering, the laboratory of economics and management neglects the characteristics of experiment. Construction is not in place; management is not perfect, a direct impact on the quality of experimental teaching to further improve. Secondly, with the increase of the experimental time, the experimental teaching resources are tense from the classroom experiment to the extra-curricular opening. Lab resources sharing is not enough.

\section{Reforming Scheme and Methods}

Clear the Objectives and Functions of Laboratories Construction, and Increase the Construction of Infrastructure. The experiment teaching is an effective way to cultivate the compound economic management professionals and the talents of applied management. The laboratory is an important institution to carry through personnel training, teaching and scientific research, and academic communication. The infrastructure construction of laboratories includes laboratory site, hardware, and basic software and so on. First, establish a comprehensively open experimental environment. The cultivation of economic management personnel must meet the needs of the society, and the construction of innovative laboratories must also meet the requirements of the times. Combining the traditional laboratory with the modern computer technology, network communication technology, multimedia technology and other information processing and communication technology is the comprehensively open experiment environment based on experimental teaching and learning. Second, develop the professional management software. The management software is mainly used for innovative laboratory configuration software such as the development and design of simulation of the operation of the enterprise physical sand table, electric sand table, and sand table confrontation exercise comprehensive evaluation system software; ERP professional application software, e-commerce simulation, document simulation, 
marketing, logistics and supply chain simulation software, which have the same simulation software with the real enterprise, can stimulate students' interest in learning, active participation in teaching experiments and practical activities to help students develop innovative awareness.

People-oriented, Strengthen the Construction of Experimental Teaching Staff. The experimental teachers are the main power to complete the experimental teachings. The construction of a team of good quality, reasonable structure, and strong sense of the experimental teaching staff is the basic guarantee of laboratory teaching and laboratory work. Experimental teaching staff includes professional experimental teachers, laboratory technicians, and laboratory management personnel. Colleges and universities for the sake of saving capital or resources, often require every one laboratory teacher have both professional knowledge and the ability of laboratory management and maintenance, which will cause higher requirements of the experimental teaching staff. Therefore, it is very important to cultivate a team of good and stable experimental teaching staff. And it is essential to establish a fair and reasonable distribution system and incentive system. Schools should attach importance to the role of experiment teaching staff, to give a positive financial and technical support, reasonable lab personnel training plan, and the existing experimental staff on-the-job training, education and academic exchanges, give them more opportunity to learn and study, cultivate technology and understand experiment teachers. In the title assess and post grade appraisal should be provided incentives, meanwhile, change the lack of experiment teaching staff, unreasonable structure.

Strengthen the Construction of Experimental Teaching System. First, change the teaching concept. Change the traditional theory teaching and experiment teaching, which is complementary as old ideas. The theory teaching and practice teaching as a full accord, which could support each other, complement each other. Theory focuses on the operation skills and innovation ability, Transform the wrong view, such as the theory teaching level is high, and the experimental teaching as "low level", improve higher levels of experiment teaching staff and tightening of existing staff training at the same time, meanwhile improve the overall level of experimental teaching; Positive experiment personnel innovation concept should be stimulated, establish special experimental research foundation, use experimental study of reform courses, experiment method, arouse the enthusiasm of the innovation of the experimenter. Second, Optimization of the course offered. Professional course of experiment teaching should be thoroughly got rid of the affiliated status as a theory, design independently to set experimental teaching course. Break the past way curriculum organization experiment content, and according to the similar subjects, inner link of experiment content and give full play to students' innovative ability. Experimental types can be composed of verification, comprehensive and innovative experiments, three parts respectively to achieve certain goals. Confirmatory experiment training students' basic skills , the understanding of theoretical knowledge, and comprehensive experiments ,they can reflect student's knowledge, ability and the understanding of theoretical knowledge, comprehensive experiments mainly used and designed by the students', focus on the students innovative thinking of play and the cultivation of innovation ability. The curriculum innovation to starting conditions, equipment, on the basis of summing up experience, gradually popularized to other areas. Third, reform the teaching method. Use different types, different levels methods of experiment teaching cultivate students' innovation consciousness, innovation ability and practice ability. "Demonstration experiment" teaching mode, cultivate students familiar with the operation process of experimental equipment and experimental, demonstration and the Internet can be used, such as multimedia, slide show; "Simulation experiment" teaching methods, students participate main course test or internship, under the guidance of the teacher, and finally finish the whole process of experiment by their own, then attempts to solve the various problems in the experiment of independently; "Open experiment" teaching methods, mainly to let the students give full play to the imagination, using professional knowledge to design experiment scheme with unique style. Teaching method is one of the main 
forms of training applied and innovative talents. Last, carefully design simulated experiment. Simulated practice in campus belongs to the category of graduation practice or comprehensive practice, that focus on training students to get gradually the comprehensive decision-making ability and innovation ability when engaging in economic management. Elaborately designing and developing scientific simulation training system around the enterprise operation rouses rapidly the students for the sense of identity to jobs and the environment. Such as simulating Production, industrial and commercial bureau, tax bureau, bank, talent exchange center, etc. Through experiencing the basic business processes and links of the relevant functional departments, the students can study and familiar with operations of industrial and commercial tax registration, tax and other business, meanwhile can understand the settlement and loans. Also they could learn the economic disputes and arbitrations of the legal department. By simulating and emulating such experimental operations, that make the students deepen the understanding of theoretical knowledge, be familiar with the ability to apply for specific jobs, which can raise the level of compound talent ' $\mathrm{s}$ training , and improve the whole competitiveness and abilities of adapting to the work in the future for college students.

Build Network of Intelligent Management System; Strengthen the Organization and Management of Laboratory Construction. First, establish the network experimental teaching system. Schools should establish a network platform; the related management class should be established and based on campus network laboratory dedicated server. The network experimental teaching management concludes two parts: hardware and software. Hardware $s$ used in the experiment teaching of computers, servers, switches, etc. Software refers to the related experiment teaching, experiment instruction, and also can be used to manage the experimental teaching courses courseware application, etc. The basic function of network laboratory can be well revealed in experimental facilities. Schools can set up an experiment teaching website, on the function should include the following six aspects: laboratory use reservation system; Introduction of laboratory function; the courseware and the experimental data; related software and download the client; using experimental software; Information exchange platform between teachers and students. By the school's experiment, students can study website for what they need. Second, realize the resources sharing. For internal lab, at the beginning of each semester, according to the teaching plan, devices configured should be conformed to the requirements of teaching condition, ensure the normal order of the laboratory experiment. In needs to be done outside of the laboratory simulation experiment, students can set up the related area in the server for the use of students, including software download area, data of the experiment content, students kept area, etc. Students can be accessed through any computer network laboratory site, on the basis of the content of related experiments; Teachers can use of multimedia teaching methods in class, they could present teaching way. Last, teaching management innovation. To improve the experimental teaching management by adopting the combination of centralized management and decentralized management mode. Centralized management is mainly manifested in the laboratory construction, which is implemented and unified by school. Decentralized management mainly reflected in the implementation of the experimental teaching. Secondary schools will be responsible for recognition, teaching plan and the arrangement of the content implemented of the experimental courses.

\section{Acknowledgements}

Yulin College Teaching Reform Project in 2016(JG1634)

\section{References}

[1] L. Li: Journal of National Academy of Education Administration, Vol. 16 (2009) No.1, p.82 (In Chinese)

[2] L.H. Jiang and X. Cai: Research and Exploration in Laboratory, Vol. 29 (2010) No.1, p.178 (In 
Chinese)

[3] H.M. Wang and H.W. Li: Experimental Technology and Management, Vol. 28 (2011) No.7, p.279 (In Chinese)

[4] L. Ren and Z.Y. Wang: Research and Exploration in Laboratory, Vol. 34 (2015) No.7, p.254 (In Chinese)

[5] L.J. Zhang and B.R. Wu: Experimental Technology and Management, Vol. 31 (2014) No.6, p.162 (In Chinese)

[6] X. Cai and F.J. Liu: Research and Exploration in Laboratory, Vol. 30 (2011) No.4, p.166 (In Chinese)

[7] X.B. Zeng: Research: Exploration in Laboratory, Vol. 27 (2008) No.9, p.1 (In Chinese)

[8] H.Y. Jia: Research and Exploration in Laboratory, Vol. 27 (2008) No.1, p.156 (In Chinese)

[9] L.Y. Du, R. Ma, Y.T. Xu and SH.H. Zhou: Research and Exploration in Laboratory, Vol. 32(2013) No10, p.197 (In Chinese)

[10] H.W. Li: Experimental Technology and Management, Vol. 33 (2016) No.6, p.225 (In Chinese)

[11] L.J. Zhang, X.J. Zhu and J.M. Gao: Research and Exploration in Laboratory, Vol. 34 (2015) No.2, p.269 (In Chinese) 